\title{
Make It Measurable: Assessing Psychological Distress, Wellbeing and Resilience at Scale in Higher Education
}

\author{
Joep van Agteren \\ South Australian Health and Medical Research Institute (SAHMRI)/ Flinders University, Adelaide, Australia \\ Lydia Woodyatt \\ Flinders University, Adelaide, Australia \\ Matthew Iasiello \\ South Australian Health and Medical Research Institute (SAHMRI)/ Flinders University, Adelaide, Australia \\ Julie Rayner \\ Flinders University, Adelaide, Australia \\ Michael Kyrios \\ Flinders University, Adelaide, Australia
}

\begin{abstract}
There is an ever-increasing focus on the importance of addressing the mental health of students across the higher education sector. Measuring psychological distress or symptoms of common mental disorders as a proxy for mental health does however provide a limited picture of someone's mental health status. There is a need to comprehensively measure mental health via outcomes of psychological distress combined with "positive" and "adaptive" states of mental health such as mental wellbeing and resilience. This paper describes a study of 905 students in which an online mental health and wellbeing platform was used to measure the mental health of students, all the while providing realtime individual reports to each individual student. The data provides evidence of high levels of psychological distress (i.e. anxiety) and low levels of mental wellbeing and resilience in students, relative to population norms, with merely $18.6 \%$ of students demonstrating optimal scores on all outcomes. Contrary to predictions we found no evidence of poorer wellbeing amongst international students when compared to domestic students. The results indicate that complimenting measurement of distress with measurement of positive and adaptive states can more comprehensively capture the precarious mental status of our tertiary students. Providing this measurement in a scalable and targeted way provides universities and its students the opportunity to provide and use mental health interventions based on the needs of particular cohorts of students, moving beyond resource-intense but intermittent or untargeted approaches to intervention.
\end{abstract}

Keywords: Mental health; resilience; wellbeing; intervention.

\section{Mental Health in Higher Education}

Having good mental health and wellbeing is important to all of us - as individuals, family members, friends, neighbours and within our communities. When we thrive, we see benefits across many aspects of our lives. Improving our mental wellbeing lowers our risk of mental and physical illness (Keyes, Dhingra, \& Simoes, 2010; Wood \& Joseph, 2010), and can speed up recovery when we do get sick (Diener, Pressman, Hunter, \& Delgadillo-Chase, 2017; Iasiello, van Agteren, Keyes, \& Cochrane, 2019). Our social lives improve and we have a higher number of positive relationships (Kansky \& Diener, 2017). When we

This work is licensed under a Creative Commons Attribution 4.0 International Licence. As an open access journal, articles are free to use with proper attribution. ISSN: 2205-0795 
have higher levels of mental wellbeing our productivity increases, which can translate to better academic outcomes (Huppert, 2009).

Many researchers are proposing that issues of psychological distress are on the rise amongst university students (Orygen, 2017; Scott-Young, Turner, \& Holdsworth, 2018). This can have implications for student success as it may form a significant barrier to retention, completion, and achievement. The impact of managing psychological distress during the study period extends beyond university life, with research links to outcomes like employability and wellbeing at work, both presently and in the future (Scott-Young et al., 2018). Carter, Paliano, Francis \& Thorne (2017) for instance suggested that mental health difficulties follow students when transitioning into employment and subsequently lead to lifelong negative impacts. Given this, it should perhaps be unsurprising that students see their mental health not just as a means to success, but as a key outcome by which they measure their own success (O’Shea \& Delahunty, 2018).

The impact of psychological health on students and their success has led to recommendations to implement institution-wide approaches to support student wellbeing and mental health across the university sector (Orygen, 2017; Okanagan Charter, 2015). However, in order for the Higher Education sector to make progress on this issue, student wellbeing and mental health needs to be "made measurable" (Orygen, 2017). Despite millions of dollars spent in student support, it has proven challenging to reliably measure and track change in mental health and wellbeing outcomes across the sector or within an institution (Carter et al., 2017). Firstly, a challenge for assessment of wellbeing and mental health across higher education is balancing questionnaire burden with sufficient validity to allow for evidence-based decisions to be made in relation to the mental health of the student group. Secondly, higher education institutions have a duty of care to ensure students are cognisant of their current distress status, but are similarly aware of their mental wellbeing and resilience status, and to provide students with resources or interventions that can be used to improve the experience of their mental health status.

\section{What Needs to be Measured when Assessing Mental Health in Higher Education (and why)}

\section{Psychological Distress}

The vast majority of research on mental health in higher education investigates psychological distress symptoms. Psychological distress, which focuses on distress resulting from symptoms associated with depression, anxiety or stress, has been associated with significant reductions in academic performance and engagement (Andrews \& Wilding, 2004; Stallman, 2010). Students that experience high psychological distress are significantly impacted in their capacity to study, with research showing that, on average, students using university health services are prevented from work or study for 8 days over a 4-week period as a result of their distress (Stallman, 2008). Further, research suggests students may experience these symptoms at higher levels than the general population. For example, in a survey of more than 5,000 students at the University of Melbourne in Australia, Larcombe et al. (2016) found that students reported elevated levels of stress, anxiety and depression relative to population norms.

Symptoms of psychological distress are often aggregated into a single score, thereby capturing psychological distress as a total construct. For example, screening tools such as the Mental Health Inventory (MHI)-5 (Berwick et al., 1991) or the popular Kessler (K)-10 (Kessler et al., 2002) have the benefit of being validated and are readily used in Australia, but do not breakdown scores for the independent subdomains of depression, anxiety or stress independently. An aggregated score of psychological distress can be useful to show a wider mental health need but reduces the ability of a person or organisation to respond to particular outcomes through targeted intervention. While symptoms associated with depression and anxiety share common and differential antecedents (Eysenck \& Fajkowska, 2018), they show differences in their relationship to mental wellbeing (Iasiello, van Agteren, \& Muir-Cochrane, forthcoming) and similarly may influence outcomes related to student success differentially. Thus, although there is a need to assess psychological distress, there is a need to do so in a nuanced way that leads to a specific indication of the mental health need.

\section{Mental Wellbeing and Resilience}

Capturing psychological distress only highlights one aspect of the overall mental health of students. It is similarly necessary to measure "positive" and "adaptive" mental health outcomes such as mental wellbeing and resilience (Suldo \& Shaffer, 2008). Mental wellbeing is related to but distinct from the absence of psychological distress and mental illness and is an important resource for student success (Denovan \& Macaskill, 2017; Iasiello et al., forthcoming). Mental wellbeing (which can encompass 
a range of positive emotional and motivational states) can significantly impact student success, as demonstrated in a several studies. In a longitudinal study of students across four years of study in Hong Kong, good mental wellbeing was associated with higher levels of engagement and subsequent learning outcomes (Yu, Shek \& Zhu, 2018). Students showing better adjustment to university life during their first 6 months of study experience higher mental wellbeing (compared to those with poorer adjustment), which is associated with higher academic performance (Baily \& Phillips, 2016).

Mental wellbeing describes the more "positive" aspects of human emotional and motivational states. Measures of mental wellbeing are typically classified as either hedonic or eudaimonic. Hedonic measures of wellbeing generally focus on subjective feelings of wellbeing (as in the presence of positive affect or positive motivational states, the absence of negative affect or negative motivational states and the presence of life satisfaction) (Diener, 1984). Eudaimonic wellbeing focusses instead on the experience of positive functioning, including aspects such as autonomy, personal growth, and a sense of meaning in life (Ryff \& Keyes, 1995). When measuring the wellbeing of university students, both hedonic and eudaimonic aspects of wellbeing should be measured to capture a holistic image of student wellbeing. Imagine a student who is goal orientated, and feels that they are learning new things and have purpose, and yet they do not experience subjective feelings of happiness or enjoyment. Difficult emotions, failure, and frustrations may be part of the learning environment when one is challenged, but if this is associated with a growing sense of connection to others, purpose, or growth, even these negative feelings can be part of wellbeing (Kashdan \& Biswas-Diener, 2014).

Where hedonic and eudaimonic wellbeing focus on individual feelings and ability to self-realise, social wellbeing describes one's wellbeing in relation to their community (e.g. the student population) or society. Social health or wellbeing has traditionally been an important aspect of sociological theory (Durkheim, 2005), and has been integrated into overall mental wellbeing (Keyes, 2002; Keyes, 1998). Social wellbeing describes one's appraisals of their circumstances and functioning in society. Broadly, it includes domains of social integration, social acceptance, social contribution, social actualisation, and social coherence, which have been described elsewhere (Keyes, 1998). While some research has investigated the conceptual overlap between student social wellbeing and sense of community and participation in university community (Cicognani et al., 2008), it is often overlooked in university student mental health research in favour of isolation and loneliness (Houghton, Hattie, Carroll, Wood, \& Baffour, 2016). Social wellbeing may be particularly relevant for international students who may be least likely to participate in the university community and report higher levels of loneliness and isolation (Alsahafi \& Shin, 2016; Macionis, Walters, \& Kwok, 2018).

Irrespective of current levels of psychological distress and wellbeing, students need to possess the ability to cope with and restore from the stressors or adversity that are inevitable parts of student life (Davydov, Stewart, Ritchie, \& Chaudieu, 2010). The student's perceived ability to manage the stressors in their life, defined here as resilience, is a valuable outcome to measure. If high levels of resilience are present, the student is better protected from developing low levels of wellbeing or distress in the future. It is therefore unsurprising that resilience has been linked to student success at university (Baik et al., 2017; Stamp et al., 2015) and can provide valuable insight in identifying at-risk students. For example, students may not be experiencing worrisome stress levels at the moment but may feel that they could not deal with stress when it would arise in the future. Measuring students early in the semester may not highlight issues with stress, but if the student has low resilience, this can flag potential challenges in the future, e.g. closer to exam periods.

\section{The Current Study}

Taking this more comprehensive and nuanced approach to student mental health measurement can provide greater insight into the student experience and can better inform student mental health interventions (Iasiello et al., forthcoming). For example, a student may experience heightened stress during their studies, but if this is balanced by resilience, high subjective wellbeing, and positive coping behaviours then the student may still be experiencing positive mental health. Another student may experience low levels of stress or anxiety, but also low feelings of subjective wellbeing (low on purpose, growth, or happiness) and may be at risk of poor mental health. Studies in high school students consistently show that measuring both well-being and distress outcomes can identify sub-groups of students that are at risk of low academic performance including lower attendance rates, academic scores, self-efficacy and academic self-perceptions (Rose, Lindsey, Xiao, Finigan-Carr, \& Joe, 2017; Suldo, Thalji, \& Ferron, 2011; Suldo \& Shaffer, 2008; Venning, Wilson, Kettler, \& Eliott, 2013; Xiong, Qin, Gao, \& Hai, 2017). Studies with university students are less common, identifying the need to determine the impact of these outcomes on student success in this population. 
The current study attempts to make mental health - encompassing wellbeing, resilience and distress - measureable. Given that local educational contexts may impact on student psychological wellbeing, the study was conducted with the aim of getting insight into local psychological wellbeing and distress levels, as the first stage of developing a targeted student mental health and wellbeing program. Given previous research it was expected that psychological distress would be higher amongst university students relative to population norms. Similarly, it was hypothesised that wellbeing would be lower, as well as the general resilience of the students compared to general norms. Furthermore, the impact of various moderators was investigated. For instance, it was expected that the mental health and wellbeing of international students would be lower than that of domestic students, as research suggests that the wellbeing of international student is worse than that of domestic students due to the range of pressures and stressors such as learning new cultural norms, language barriers, level of engagement with the host society, loneliness, financial security, and accommodation concerns (Han, Han, Luo, Jacobs, \& Jean-Baptiste, 2013; Leung, 2001; Poyrazli \& Grahame, 2007; Wu, Garza, \& Guzman, 2015).

\section{Methods}

\section{Participants}

During the months of March to April 2019, the entire student population from the disciplines of Education, Psychology and Social Work at Flinders University $(\mathrm{n}=5791)$ in Australia were invited to participate in a measure of mental health and wellbeing. Students were invited via student newsletters, direct email, announcements in lectures and by asking academic staff to promote the wellbeing survey directly to their students. Within a three-week response period, a sample of $n=905(15.6 \%)$ students completed a baseline measure.

\section{Approach}

The study was a collaborative project between the university and the South Australian Health and Medical Research Institute (SAHMRI), which specialises in the measurement of intervention in mental health and wellbeing. SAHMRI has developed a specialised technology platform (app.completementalhealth.com) which has been designed according to the highest privacy standards (e.g. the platform is General Data Protection Regulation (GDPR) compliant) to ensure individual participant anonymity and privacy. Students were invited to log into the platform via mobile-enabled devices on a browser that adhered to modern web standards. Communication from both the university and SAHMRI, was devised to ensure that the student understood that an external research institute was guardian of the data. Students were directed to take the measurement online, which took roughly 10 to 15 minutes to complete.

The platform, in addition to acting as a measurement tool, had the aim to improve student mental health and wellbeing literacy (Oades, 2017). Each student who completed the measurement received an in-depth online report that summarised the student's scores on each of the outcomes, provided an explanation for each of the domains and gave recommendations on activities to complete when scores warranted improvement. The report was accessible in real-time on the platform after completing the measurement. In addition to the tailored report, students could read a variety of wellbeing and mental health related content accessible on the platform's homepage. Finally, information regarding university wide health, mental health and wellbeing resources and services was sent to students as part of the questionnaire procedure.

\section{Data Analysis}

A variety of statistical techniques were used in this study including independent samples, t-tests, Chi-Square tests, analysis of Variance (ANOVA) and Analysis of Covariance (ANCOVA) to control for relevant covariates where necessary. While normality of scores is typically an issue for wellbeing measures, ANOVA is relatively robust to a violation of normality, leading to the decision to retain the original scores as opposed to conducting transformations to the data. Where possible, documented cut-offs were used to form categorisations into risk-groups or to help infer severity of symptoms in the presented graphs. 


\section{Results}

A breakdown of demographic information on the participants is displayed in Table 1. The respondent sample was largely representative of the total student population, with gender proportions (female: sample $84.1 \%$, student population $73.8 \%$ ) being the only variable that was different between the participant sample and the overall student population. The majority of respondents were Australian citizens, who overwhelmingly identified as non-indigenous (99.1\%), with the proportion of international students in the sample being $12.4 \%$.

\section{Table 1}

Demographic Information on Student Population at Measurement

\begin{tabular}{|c|c|c|c|c|}
\hline & $\begin{array}{c}\text { Education } \\
\text { students }\end{array}$ & $\begin{array}{l}\text { Psychology } \\
\text { students }\end{array}$ & $\begin{array}{l}\text { Social Work } \\
\text { Students }\end{array}$ & Entire Sample \\
\hline$n$ & 370 & 293 & 242 & 905 \\
\hline Response rate & $11 \%$ & $26 \%$ & $18 \%$ & $16 \%$ \\
\hline \multicolumn{5}{|l|}{ Gender } \\
\hline Female & 300 & 248 & 212 & 759 \\
\hline Male & 70 & 45 & 30 & 144 \\
\hline Other & - & - & - & - \\
\hline \multicolumn{5}{|l|}{ Age } \\
\hline $18-24$ & 234 & 217 & 86 & 537 \\
\hline $25-34$ & 76 & 43 & 92 & 211 \\
\hline $35-44$ & 23 & 17 & 41 & 81 \\
\hline $45-54$ & 29 & 16 & 15 & 60 \\
\hline $55+$ & 6 & 0 & 8 & 14 \\
\hline \multicolumn{5}{|l|}{ Indigenous status } \\
\hline Indigenous & 4 & 2 & 2 & 8 \\
\hline Non-indigenous & 364 & 289 & 239 & 890 \\
\hline Unknown & 2 & 2 & 1 & 5 \\
\hline \multicolumn{5}{|l|}{ Citizenship } \\
\hline Australian & 354 & 289 & 149 & 791 \\
\hline International & 16 & 4 & 93 & 112 \\
\hline \multicolumn{5}{|l|}{ Course level } \\
\hline Undergraduate & 261 & 269 & 75 & 605 \\
\hline Postgraduate & 108 & 24 & 166 & 298 \\
\hline
\end{tabular}

Note: $n=$ number of participants

\section{Outcome Variables}

The mental health measurement was carefully crafted to allow for reliable and valid assessment of mental health outcomes, while reducing questionnaire burden by choosing scales with low item numbers. Wellbeing was measured using the Mental Health Continuum Short-Form (MHC-SF) (Keyes et al., 2008). The MHC-SF is a valid and reliable measure of wellbeing, providing both a continuous measure of three key domains of wellbeing (hedonic, eudaimonic, and social wellbeing), as well as a "diagnosis" of overall wellbeing into "flourishing" or high wellbeing, moderate wellbeing and "languishing" or low wellbeing. Internal reliability was conducted on the summed total score of all 14-items $(\alpha=.921)$.

Psychological distress was measured using the Depression Anxiety and Stress Scale - 21 items (DASS-21) (Henry \& Crawford, 2005). The DASS-21 has clear cut-off points for level of severity of symptoms, allowing grouping of scores into "mild", "moderate", "severe", and "extremely severe" symptoms of psychological distress. Analysis was conducted using total scores for each of the three domains: depression $(\alpha=.909)$, anxiety $(\alpha=.842)$, and stress $(\alpha=.807)$. 
Finally, the student's own interpretations of their ability to deal with and bounce back from stress or adversity (i.e. resilience) was measured using the Brief Resilience Scale (BRS) (Smith et al., 2008). The BRS conceptualises resilience as an outcome and is a well-accepted tool to gain insight into resilience, with cut-offs for low, normal and high resilience (Windle, Bennett, \& Noyes, 2011). Participants answered 6 questions on a 1 (Strongly disagree) to 5 (Strongly Agree) scale (e.g., I tend to bounce back quickly after hard times; $(\alpha=.839)$.

Mental Wellbeing (Flourishing) correlated $r=0.516$ with resilience, while correlating between -.491 and -.515 with stress and anxiety. The correlation between positive mental health and depressive symptoms was higher than expected at $r=-.741$, which has been observed in other cohorts with high severity of symptoms (van Erp Taalman Kip \& Hutschemaekers, 2018). The constructs of psychological distress were correlated between .615 and .734 .

\section{Wellbeing, Resilience and Distress in Total Sample}

Scores on the MHC-SF found that only $30 \%$ of student responders had high wellbeing, 59.91\% had moderate wellbeing and 9.08\% were languishing (see Figure 1). Resilience scores for the sample indicated that almost half of the sample (45\%) displayed low levels of resilience, with $51 \%$ demonstrating normal levels of resilience and $4 \%$ indicating high levels of resilience. Average psychological distress scores indicated that a relatively large proportion of students display psychological distress levels that are at mild or above levels, 57\% for depression, $62 \%$ for anxiety and 52\% for stress. Looking at scores for students displaying moderate or above symptoms of psychological distress, it was found that $65 \%$ of the student population met the requirements for at least one of the three types of distress. The large proportion could be attributed to scores on anxiety and depression, as stress only accounted for $9 \%$ of the total $65 \%$. An overview of all mean scores can be found in Table 2 .

\section{Figure 1}

Proportions of students displayed per cut-off for wellbeing (left graph), resilience (middle graph) and psychological distress (right graphs)

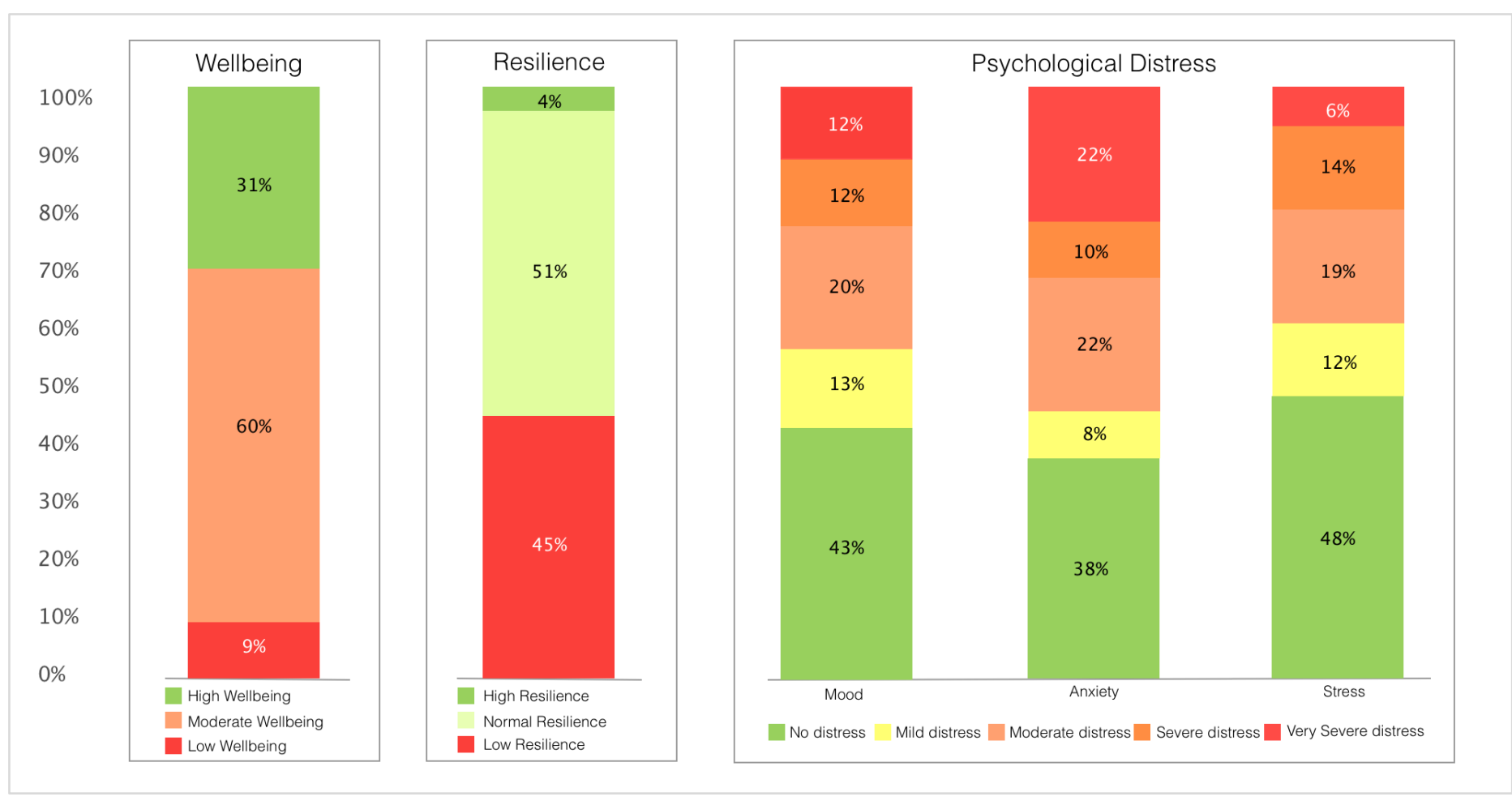




\section{Table 2}

Unadjusted mean scores and standard deviations (in brackets) for all domains, overall and split for gender, age, internationality. Significance values are reported next to each sub-group with significance (displayed in bold)

\begin{tabular}{|c|c|c|c|c|c|c|c|c|c|c|c|c|c|}
\hline & \multicolumn{3}{|c|}{ Gender } & \multirow[b]{2}{*}{ Sig. } & \multicolumn{5}{|c|}{ Age } & \multicolumn{3}{|c|}{ Internationality } & \multirow[b]{2}{*}{ Sig. } \\
\hline & Overall & Male & Female & & $18-24$ & $25-34$ & $35-44$ & $45-54$ & $55+$ & Sig. & Domestic & International & \\
\hline Overall Wellbeing & $\begin{array}{l}41.01 \\
(13.13)\end{array}$ & $40.73(13.2)$ & $\begin{array}{l}41.06 \\
(13.12)\end{array}$ & 0.781 & $\begin{array}{l}39.51 \\
(13)\end{array}$ & $\begin{array}{l}40.2 \\
(13.51)\end{array}$ & $\begin{array}{l}46.11 \\
(10.5)\end{array}$ & $\begin{array}{l}46.8 \\
(11.17)\end{array}$ & $\begin{array}{l}55.57 \\
(12.33)\end{array}$ & 0.00 & $\begin{array}{l}40.91 \\
(13.05)\end{array}$ & $\begin{array}{l}41.72 \\
(13.71)\end{array}$ & 0.543 \\
\hline Subjective & $\begin{array}{l}9.61 \\
(2.99)\end{array}$ & $9.29(3.35)$ & $9.68(2.91)$ & 0.152 & $\begin{array}{l}9.53 \\
(2.95)\end{array}$ & $9.29(3.1)$ & $\begin{array}{l}10.11 \\
(2.83)\end{array}$ & $\begin{array}{l}10.23 \\
(2.73)\end{array}$ & $\begin{array}{l}12.07 \\
(3.12)\end{array}$ & 0.00 & $\begin{array}{l}9.66 \\
(3)\end{array}$ & $\begin{array}{l}9.31 \\
(2.92)\end{array}$ & 0.247 \\
\hline Psychological & $\begin{array}{l}18.53 \\
(6.24)\end{array}$ & $18.59(6.32)$ & $\begin{array}{l}18.52 \\
(6.23)\end{array}$ & 0.9 & $\begin{array}{l}17.66 \\
(6.28)\end{array}$ & $\begin{array}{l}18.4 \\
(6.25)\end{array}$ & $\begin{array}{l}21.53 \\
(4.52)\end{array}$ & $\begin{array}{l}21.25 \\
(5.38)\end{array}$ & $\begin{array}{l}24.85 \\
(5.08)\end{array}$ & 0.00 & $\begin{array}{l}18.56 \\
(6.24)\end{array}$ & $\begin{array}{l}18.32 \\
(6.26)\end{array}$ & 0.696 \\
\hline Social & $\begin{array}{l}12.85 \\
(5.35)\end{array}$ & $12.84(5.32)$ & $\begin{array}{l}12.86 \\
(5.36)\end{array}$ & 0.976 & $\begin{array}{l}12.3 \\
(5.17)\end{array}$ & $\begin{array}{l}12.54 \\
(5.6)\end{array}$ & $\begin{array}{l}14.46 \\
(4.89)\end{array}$ & $\begin{array}{l}15.31 \\
(4.94)\end{array}$ & $\begin{array}{l}18.64 \\
(5.13)\end{array}$ & 0.00 & $\begin{array}{l}12.68 \\
(5.27)\end{array}$ & $\begin{array}{l}14.08 \\
(5.73)\end{array}$ & 0.009 \\
\hline \multicolumn{14}{|l|}{ Distress } \\
\hline Depression & $\begin{array}{l}13.18 \\
(10.35)\end{array}$ & $\begin{array}{l}12.72 \\
(10.25)\end{array}$ & $\begin{array}{l}13.27 \\
(10.38)\end{array}$ & 0.564 & $\begin{array}{l}14.52 \\
(10.51)\end{array}$ & $\begin{array}{l}12.94 \\
(10.32)\end{array}$ & $\begin{array}{l}9.72 \\
(9.06)\end{array}$ & $\begin{array}{l}8.88 \\
(8.21)\end{array}$ & $4.42(6.28)$ & 0.00 & $\begin{array}{l}13.47 \\
(10.47)\end{array}$ & $\begin{array}{l}11.15 \\
(9.29)\end{array}$ & 0.027 \\
\hline Anxiety & $\begin{array}{l}11.78 \\
(9.38)\end{array}$ & $11.11(9.4)$ & $\begin{array}{l}11.91 \\
(9.38)\end{array}$ & 0.354 & $\begin{array}{l}13.24 \\
(9.44)\end{array}$ & $\begin{array}{l}11.63 \\
(9.34)\end{array}$ & $\begin{array}{l}8.05 \\
(6.99)\end{array}$ & $\begin{array}{l}6.03 \\
(7.1)\end{array}$ & $2.71(2.99)$ & 0.00 & $\begin{array}{l}11.82 \\
(9.56)\end{array}$ & $\begin{array}{l}11.5 \\
(8.03)\end{array}$ & 0.73 \\
\hline Stress & $\begin{array}{l}16.86 \\
(9.35)\end{array}$ & $15.1(9.13)$ & $\begin{array}{l}17.19 \\
(9.36)\end{array}$ & 0.014 & $\begin{array}{l}17.83 \\
(9.37)\end{array}$ & $\begin{array}{l}17.11 \\
(9.37)\end{array}$ & $\begin{array}{l}14.27 \\
(8.47)\end{array}$ & $\begin{array}{l}12.81 \\
(7.76)\end{array}$ & $7.71(7.14)$ & 0.00 & $17.12(9.4)$ & $\begin{array}{l}15 \\
(8.82)\end{array}$ & 0.024 \\
\hline Resilience & $\begin{array}{l}3.6 \\
(0.91)\end{array}$ & $3.88(0.88)$ & $3.55(0.91)$ & 0.00 & $\begin{array}{l}3.52 \\
(0.89)\end{array}$ & $\begin{array}{l}3.51 \\
(0.89)\end{array}$ & $3.84(0.9)$ & $\begin{array}{l}4.11 \\
(0.84)\end{array}$ & $4.22(1.02)$ & 0.00 & $3.61(0.94)$ & $\begin{array}{l}3.56 \\
(0.64)\end{array}$ & 0.63 \\
\hline
\end{tabular}

Note: sig. = significance value. 


\section{The Overlap of At-Risk Students when Considering Psychological Wellbeing, Distress and Resilience}

From a preventative perspective, students of interest were those not currently suffering from symptoms of psychological distress, but those that demonstrate either moderate or low levels of wellbeing, or low levels of resilience. The overlap between these outcomes is depicted in Figure 2. Sixty-three percent of students met the criteria for moderate distress severity in at least one of the psychological distress domains of depression, anxiety, or stress. Only $34.4 \%$ of students reported mild or no distress for all three domains. Of these $34.4 \%$ of students reporting low levels of psychological distress, $17.9 \%$ of students reported low levels of resilience, putting them at risk of future distress as they do not feel prepared to manage the challenges in their life. Of the remaining $82.1 \%$ (28.2\% of total sample), 66\% achieved the category of flourishing mental health, which is the optimal wellbeing score. Thus, considering psychological distress, resilience, and wellbeing together - only $18.6 \%$ of students demonstrated the optimal outcome of high wellbeing, normal levels of resilience, and no or mild levels of psychological distress. When taking a less conservative approach to this analysis, by looking at students who reach the mild distress cut-off or above (scores which warrant low intensity psychological services), merely $6 \%$ of students demonstrated optimal scores.

\section{Figure 2}

The overlap of at-risk students when considering psychological wellbeing, distress, and resilience

\section{Psychological Distress}

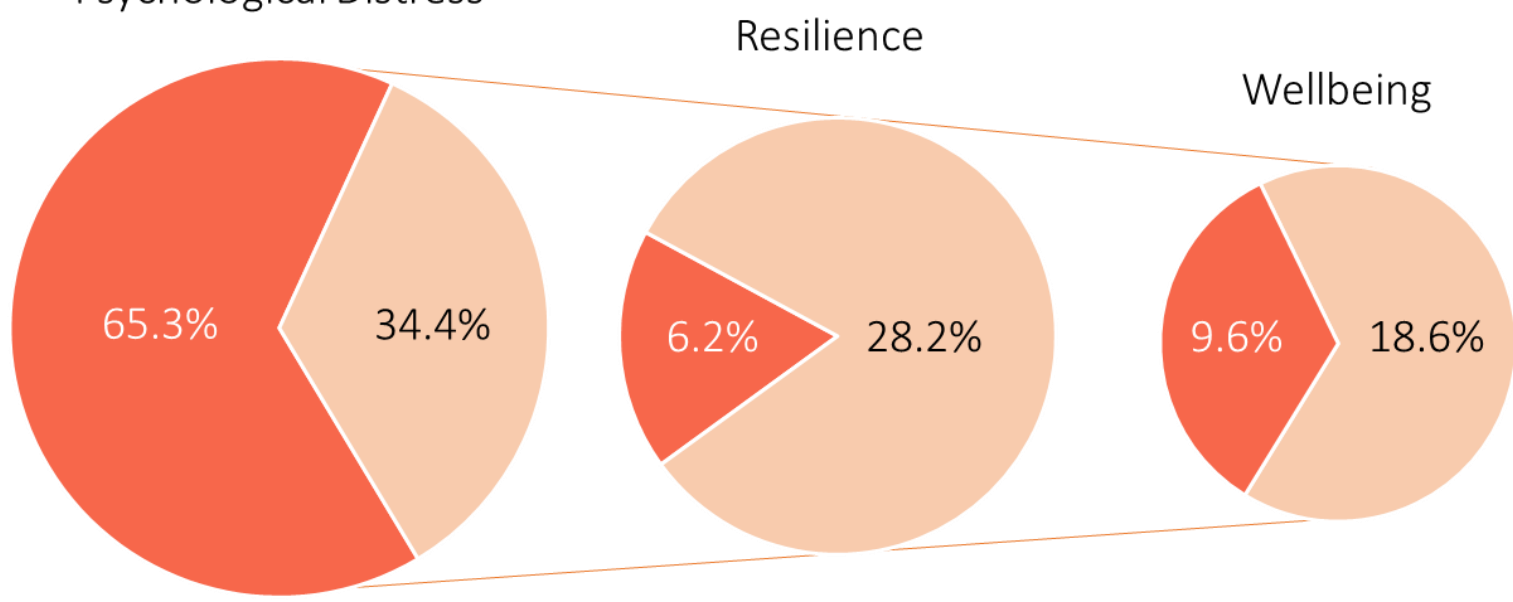

Note. Light colours represent the proportion of the total sample with optimal scores of each outcome. Successive graphs depict the breakdown of the previous optimal proportion, while the percentages reflect the proportion of the whole sample. This figure indicates that $18.6 \%$ of the total sample could be considered to have optimal mental health (no psychological distress, normal/high resilience, flourishing wellbeing) and remaining students would be considered at-risk.

\section{Influence of Moderators}

Age significantly influenced wellbeing, resilience and indicators of psychological distress, such that all outcomes tended to improve with older age. The impact of age on subjective wellbeing indicated a small effect $\left(\right.$ Partial Eta $\left.^{2}=0.02\right)$, while a moderate effect was found for social and psychological wellbeing (Partial Eta ${ }^{2}$ of 0.05 and 0.06 respectively). Similarly, a significant moderate effect of age on resilience was found (partial $\mathrm{Eta}^{2}=0.04$ ). Regarding psychological distress, the impact of age indicated moderate effects for symptoms of depression, anxiety, and stress (partial Eta ${ }^{2}$ of 0.04, 0.07, and 0.04 respectively). There were significant differences found between undergraduate and postgraduate students for all three outcomes, but after controlling for age differences neither outcome remained significant.

Gender effects differed per outcome. There were no significant differences between males and females in relation to wellbeing, on any of the three wellbeing domains. There were significant gender differences in resilience, in that women tended to have significantly lower levels of resilience compared to men $\left(p=0.00\right.$, partial Eta $\left.^{2}=0.02\right)$. Females showed significantly higher levels of psychological distress due to stress compared to males, although the effect did not reach the threshold of a small effect, 
partial $\mathrm{Eta}^{2}=0.07$. No significant gender differences were found between psychological distress as a result of mood and anxiety.

There were no significant differences in any domains of wellbeing or resilience between the domestic and international students tested. Surprisingly, domestic students scored significantly higher in distress due to mood and stress symptoms than international students, although the partial Eta ${ }^{2}$ did not reach the threshold of a small effect (partial Eta ${ }^{2}$ of 0.01 in each case). No differences were found for distress due to anxiety.

\section{Discussion}

This study demonstrated the importance of assessing mental health via measures of psychological distress as well as wellbeing and resilience. The current study found low levels of wellbeing, high levels of psychological distress and a relatively high proportion of students with low resilience in an Australian tertiary student population, with less than one fifth of the students scoring high on any of the outcomes.

The results of this sample showed evidence of distress higher than population norms. In particular, symptoms of anxiety were a significant issue for students, with one third of the population reporting severe or extremely severe levels of psychological distress. The distress levels found in the current study were higher than the typically reported values of between 20 to $25 \%$ in students and the Australian general population, but approach the results found by Stallman (2010), namely $83.9 \%$ of students displaying sub-clinical distress or higher. These rates fall within the range of reported values, as the prevalence of distress in student samples widely varies between studies. For example, medical student samples demonstrate distress estimates between 12.2 and $96.7 \%$ (Hope \& Henderson, 2014). The current study was conducted with a student population comprising 905 students, and a "stress-free" moment in the academic year for the data collection was deliberately chosen. Therefore, this study makes an important contribution to the data pointing to a high distress prevalence in the wider student population.

Two specific factors, age and internationality, showed interesting response patterns. The results found in this study suggested that older students generally were doing better than younger students. Although higher distress levels are sometimes found to be higher in younger adults (Jorm et al., 2005), wellbeing is typically considered to follow an inverted u-shape in relation to age-effects with a clear dip happening in mid-life (Steptoe, Deaton, \& Stone, 2015); a finding that does not uphold for the currently studied student population. While mature-aged entry students may experience a number of barriers to study, they may also have a set of psychological skills that can hold them in good stead for success, which may explain these results.

Contrary to expectations, international students were doing better than their domestic counterparts. While international students are often thought to be at high risk of problematic mental health, for instance due to challenges related to help-seeking behaviour (Clough, Nazareth, Day, \& Casey, 2019), their distress levels were not higher than domestic students. Although this is in line with some studies which failed to find a difference between domestic and international students in Australia (Khawaja \& Dempsey, 2008), the findings in this study warrant caution. For instance, there may have been possible limitations of language and culture that hide various cultural specific expressions of poor (or positive) mental health.

The low levels of wellbeing and resilience, both together and independent from psychological distress, are a clear target area for future intervention programs. Longitudinal studies clearly indicate that low wellbeing and resilience leads to increased risk of future mental illness (Wood \& Joseph, 2010). Similarly, high levels of wellbeing are protective for future mental illness (Keyes et al., 2010) and improving wellbeing among people with mental illness improves their rate of recovery (Iasiello et al., 2019). The current sample featured a large proportion of students with a need for improvements in resilience. These students may be psychologically unprepared for challenges and stressors, which they are almost certain to encounter in their academic and personal lives. This is not only a personal wellbeing need but will be a graduate/employability need. This data is already being used to co-design (with students and staff) an intervention that will target support of these needs. Good measurement not only highlights the need but informs targeted use of finite resources to address that need.

A variety of interventions can be considered for improving wellbeing, resilience or mental health (Bolier et al., 2013; Macedo et al., 2014), but only limited evidence exists for interventions that are designed to improve all outcomes targeted in this study. Different psychological and behavioural interventions have various intervention impact depending on different parameters, e.g. cognitive-behavioural therapy (CBT) based interventions are impactful in improving wellbeing in people with mental illness, 
but do not have the same effect in people without mental illness (Trompetter, Lamers, Westerhof, Fledderus, \& Bohlmeijer, 2017; van Agteren et al., submitted). The current student sample showed a complex pattern of individual mental health and wellbeing scores, results which indicate a need for a multi-faceted intervention that takes an individual's mental state and personal characteristics into account and matches intervention components to these characteristics. For example, students who have mental illness and are flourishing may benefit most from traditional approaches to mental illness such as CBT. Students who have moderate or low wellbeing and mental illness may benefit most from a combination of traditional approaches, newwave approaches such as acceptance and commitment therapy (ACT) or approaches aiming to improve wellbeing using positive psychological principles. Mental health complexity requires more than generic catch-all interventions. Ongoing measurement will allow for continuing identification and iterative design of wellbeing supports across a university.

The current study was limited in a number of ways. Although the sample was largely representative of the larger organisation, the response rate was less than $16 \%$. This means that conclusions for specific subsets of the population (e.g. the mental health and wellbeing of Aboriginal or Torres Strait Islander students) was limited as the sample size and power was too low. In addition, the current study is limited to one of six colleges within the larger university (encompassing Education, Psychology and Social Work) meaning that the conclusions are limited to this sub-population. Furthermore, the current study was a crosssectional study which means no cause-effect can be established and the influence of confounders and bias (e.g. the influence of timing of the study) cannot be ruled out. The study furthermore only relied on quantitative measures, which means it is impossible to determine the exact drivers of the lower psychological profile of the students, with future studies needing to focus on including a qualitative component to investigate core constructs such as stress on student success (Hurst, Baranik, \& Daniel, 2013; Robotham \& Julian, 2006).

\section{Conclusion}

The current study found high levels of distress, low levels of wellbeing and relatively low levels of resilience in this tertiary student population, with results indicating that age moderated the results on all three outcomes. The project highlights the complex interrelations between mental health and wellbeing and will serve as a foundation to inform future interventions and maximise their effectiveness and efficiency.

\section{References}

Alsahafi, N., \& Shin, S.-C. (2016). Factors affecting the academic and cultural adjustment of Saudi international students in Australian universities. Journal of International Students, 7(1), 53-72. http://doi.org/10.32674/jis.v7i1.245

Andrews, B., \& Wilding, J. M. (2004). The relation of depression and anxiety to life-stress and achievement in students. British Journal of Psychology, 95(4), 509-521. https://doi.org/10.1348/0007126042369802

Baik, C., Larcombe, W., Brooker, A., Wyn, J., Allen, L., Brett, M., ... \& James, R. (2017). Enhancing student mental wellbeing: A handbook for academic educators. Australian Government Department of Education and Training. https://melbourne-cshe.unimelb.edu.au/_data/assets/pdf_file/0006/2408604/MCSHE-Student-Wellbeing-HandbookFINAL.pdf

Bailey, T. H., \& Phillips, L. J. (2016). The influence of motivation and adaptation on students' subjective well-being, meaning in life and academic performance. Higher Education Research \& Development, 35(2), 201-216. https://doi.org/10.1080/07294360.2015.1087474

Berwick, D. M., Murphy, J. M., Goldman, P. A., Ware, J. E., Barsky, A. J., \& Weinstein, M. C. (1991). Performance of a five-item mental health screening test. Medical Care, 29(2). 169-176. http://dx.doi.org/10.1097/00005650-199102000$\underline{00008}$

Bolier, L., Haverman, M., Westerhof, G. J., Riper, H., Smit, F., \& Bohlmeijer, E. (2013). Positive psychology interventions: A meta-analysis of randomized controlled studies. BMC Public Health, 13, 119. https://dx.doi.org/10.1186/1471-2458-13$\underline{119}$ 
Carter, M. A., Pagliano, P., Francis, A., \& Thorne, M. (2017). Australian university students and mental health: Viewpoints from the literature. International Journal of Innovation, Creativity and Change, 3, 1-25.

https://www.ijicc.net/images/vol3iss3/1CarterPaglianoFrancisThorne.pdf

Cicognani, E., Pirini, C., Keyes, C., Joshanloo, M., Rostami, R., \& Nosratabadi, M. (2008). Social participation, sense of community and social wellbeing: A study on American, Italian and Iranian university students. Social Indicators Research, 89(1), 97-112. https://doi.org/10.1007/s11205-007-9222-3

Clough, B. A., Nazareth, S. M., Day, J. J., \& Casey, L. M. (2019). A comparison of mental health literacy, attitudes, and help-seeking intentions among domestic and international tertiary students. British Journal of Guidance \& Counselling, 47(1), 123-135. https://doi.org/10.1080/03069885.2018.1459473

Davydov, D. M., Stewart, R., Ritchie, K., \& Chaudieu, I. (2010). Resilience and mental health. Clinical Psychology Review, 30(5), 479-495. https://doi.org/10.1016/j.cpr.2010.03.003

Denovan, A., \& Macaskill, A. (2017). Stress and subjective well-being among first year UK undergraduate students. Journal of Happiness Studies, 18(2), 505-525. https://doi.org/10.1007/s10902-016-9736-y

Diener, E. (1984). Subjective well-being. Psychological Bulletin, 95(3), 542. http://dx.doi.org/10.1037/0033-2909.95.3.542

Diener, E., Pressman, S. D., Hunter, J., \& Delgadillo-Chase, D. (2017). If, why, and when subjective well-being influences health, and future needed research. Applied Psychology: Health and Well-Being, 9(2), 133-167. https://doi.org/10.1111/aphw.12090

Durkheim, E. (2005). Suicide: A study in sociology. Routledge.

Eysenck, M. W., \& Fajkowska, M. (2018). Anxiety and depression: Toward overlapping and distinctive features. Cognition and Emotion: Special issue on Anxiety and Depression, 1391-1400. https://doi.org/10.1080/02699931.2017.1330255

Han, X., Han, X., Luo, Q., Jacobs, S., \& Jean-Baptiste, M. (2013). Report of a mental health survey among Chinese international students at Yale University. Journal of American College Health, 61(1), 1-8. https://doi.org/10.1080/07448481.2012.738267

Henry, J. D., \& Crawford, J. R. (2005). The short-form version of the Depression Anxiety Stress Scales (DASS-21): Construct validity and normative data in a large non-clinical sample. British Journal of Clinical Psychology, 44(2), 227239. https://doi.org/10.1348/014466505X29657

Hope, V., \& Henderson, M. (2014). Medical student depression, anxiety and distress outside North America: A systematic Review. Medical Education, 48(10), 963-979. https://doi.org/10.1111/medu.12512

Houghton, S., Hattie, J., Carroll, A., Wood, L., \& Baffour, B. (2016). It hurts to be lonely! Loneliness and positive mental wellbeing in Australian rural and urban adolescents. Journal of Psychologists and Counsellors in Schools, 26(1), $52-67$. https://doi.org/10.1017/jgc.2016.1

Huppert, F. A. (2009). Psychological well-being: Evidence regarding its causes and consequences. Applied Psychology: Health and Well-Being, 1(2), 137-164. https://doi.org/10.1111/j.1758-0854.2009.01008.x

Hurst, C. S., Baranik, L. E., \& Daniel, F. (2013). College student stressors: A review of the qualitative research. Stress and Health, 29(4), 275-285. https://doi.org/10.1002/smi.2465

Iasiello, M., van Agteren, J., Keyes, C. L. M., \& Cochrane, E. M. (2019). Positive mental health as a predictor of recovery from mental illness. Journal of Affective Disorders, 251, 227-330. https://doi.org/10.1016/j.jad.2019.03.065

Iasiello, M., van Agteren, J., \& Muir-Cochrane, E. (Forthcoming). Mental health and/or mental illness: A scoping review of the evidence and implications of the dual-continua model of mental health. Evidence base.

Jorm, A. F., Windsor, T. D., Dear, K. B. G., Anstey, K. J., Christensen, H., \& Rodgers, B. (2005). Age group differences in psychological distress: The role of psychosocial risk factors that vary with age. Psychological Medicine, 35(9), 12531263. https://doi.org/10.1017/S0033291705004976

Kansky, J., \& Diener, E. (2017). Benefits of well-being: Health, social relationships, work, and resilience. Journal of Positive Psychology and Wellbeing, 1(2), 129-169. http://www.journalppw.com/index.php/JPPW/article/view/20

Kashdan, T., \& Biswas-Diener, R. (2014). The upside of your dark side: Why being your whole self-not just your "good" selfdrives success and fulfilment. Penguin.

Kessler, R. C., Andrews, G., Colpe, L. J., Hiripi, E., Mroczek, D. K., Normand, S.-L., . . Zaslavsky, A. M. (2002). Short screening scales to monitor population prevalences and trends in non-specific psychological distress. Psychological medicine, 32(6), 959-976. http://dx.doi.org/10.1017/S0033291702006074

Keyes, C. L. M. (1998). Social well-being. Social Psychology Quarterly, 61(2), 121-140. http://dx.doi.org/10.2307/2787065

Keyes, C. L. M. (2002). The mental health continuum: From languishing to flourishing in life. Journal of Health and Social Behavior, 42(2), 207-222. doi: 10.2307/3090197 
Keyes, C. L. M., Dhingra, S. S., \& Simoes, E. J. (2010). Change in level of positive mental health as a predictor of future risk of mental illness. American Journal of Public Health, 100(12), 2366-2371. https://doi.org/10.2105/AJPH.2010.192245

Keyes, C. L. M., Wissing, M., Potgieter, J. P., Temane, M., Kruger, A., \& van Rooy, S. (2008). Evaluation of the mental health continuum-short form (MHC-SF) in Setswana-speaking South Africans. Clinical Psychology and Psychotherapy, 15(3), 181-192. https://doi.org/10.1002/cpp.572

Khawaja, N. G., \& Dempsey, J. (2008). A comparison of international and domestic tertiary students in Australia. Journal of Psychologists and Counsellors in Schools, 18(1), 30-46. https://doi.org/10.1375/ajgc.18.1.30

Larcombe, W., Finch, S., Sore, R., Murray, C. M., Kentish, S., Mulder, R. A., . . Williams, D. A. (2016). Prevalence and socio-demographic correlates of psychological distress among students at an Australian university. Studies in Higher Education, 41(6), 1074-1091. https://doi.org/10.1080/03075079.2014.966072

Leung, C. (2001). The psychological adaptation of overseas and migrant students in Australia. International Journal of Psychology, 36(4), 251-259. https://doi.org/10.1080/00207590143000018

Macedo, T., Wilheim, L., Goncalves, R., Coutinho, E. S. F., Vilete, L., Figueira, I., \& Ventura, P. (2014). Building resilience for future adversity: A systematic review of interventions in non-clinical samples of adults. BMC Psychiatry, 14, 227. https://dx.doi.org/10.1186/s12888-014-0227-6

Macionis, N., Walters, G., \& Kwok, E. (2018). International tertiary student experience in Australia: A Singaporean perspective. Journal of Hospitality, Leisure, Sport \& Tourism Education, 25, 100174 https://doi.org/10.1016/j.jhlste.2018.10.002

Oades, L. G. (2017). Wellbeing literacy: The missing link in positive education. n M. A. White, G. R. Slemp, \& A. S. Murray (Eds.) Future directions in well-being (pp. 169-173). Springer. https://doi.org/10.1007/978-3-319-56889-8_29

Okanagan Charter. (2015, June 22-25). An international charter for health promoting universities and colleges [Paper presentation]. 2015 International Conference on Health Promoting Universities and Colleges/VII International Congress Kelowna, BC, Canada. https://open.library.ubc.ca/cIRcle/collections/53926/items/1.0132754

Orygen. (2017). Under the radar: The mental health of Australian university students. https://www.orygen.org.au/Policy/Policy-Reports/Under-the-radar

O'Shea, S., \& Delahunty, J. (2018). Getting through the day and still having a smile on my face! How do students define success in the university learning environment? Higher Education Research \& Development, 37(5), 1062-1075. https://doi.org/10.1080/07294360.2018.1463973

Poyrazli, S., \& Grahame, K. M. (2007). Barriers to adjustment: Needs of international students within a semi-urban campus community. Journal of Instructional Psychology, 34(1), 28-45.

Robotham, D., \& Julian, C. (2006). Stress and the higher education student: a critical review of the literature. Journal of Further and Higher Education, 30(2), 107-117. https://doi.org/10.1080/03098770600617513

Rose, T., Lindsey, M. A., Xiao, Y., Finigan-Carr, N. M., \& Joe, S. (2017). Mental health and educational experiences among Black youth: A latent class analysis. Journal of Youth and Adolescence, 46(11), 2321-2340. http://dx.doi.org/10.1007/s10964-017-0723-3

Ryff, C. D., \& Keyes, C. L. M. (1995). The structure of psychological well-being revisited. Journal of Personality and Social Psychology, 69(4), 719. https://doi.org/10.1037//0022-3514.69.4.719

Scott-Young, C. M., Turner, M., \& Holdsworth, S. (2018, 3-5 September). Fit for work? Comparative mental health of built environment undergraduates [Paper presentation] ARCOM 2018: Mental Health, Stress and Wellbeing. Belfast, Northern Ireland.

https://pdfs.semanticscholar.org/ac8d/1f01536fc92e47e1040a89aa4d79871d2b84.pdf?_ga=2.133271821.2073837584.157 5508720-24918857.1564631929

Smith, B. W., Dalen, J., Wiggins, K., Tooley, E., Christopher, P., \& Bernard, J. (2008). The brief resilience scale: Assessing the ability to bounce back. International Journal of Behavioral Medicine, 15(3), 194-200.

https://doi.org/10.1080/10705500802222972

Stallman, H. M. (2008). Prevalence of psychological distress in university students: Implications for service delivery. Australian Family Physician, 37(8), 673.

Stallman, H. M. (2010). Psychological distress in university students: A comparison with general population data. Australian Psychologist, 45(4), 249-257. https://doi.org/10.1080/00050067.2010.482109

Stamp, E., Crust, L., Swann, C., Perry, J., Clough, P., \& Marchant, D. (2015). Relationships between mental toughness and psychological wellbeing in undergraduate students. Personality and Individual Differences, 75, 170-174.

https://doi.org/10.1016/j.paid.2014.11.038 
Steptoe, A., Deaton, A., \& Stone, A. A. (2015). Subjective wellbeing, health, and ageing. The Lancet, 385(9968), 640-648. https://doi.org/10.1016/S0140-6736(13)61489-0

Suldo, S., Thalji, A., \& Ferron, J. (2011). Longitudinal academic outcomes predicted by early adolescents' subjective wellbeing, psychopathology, and mental health status yielded from a dual factor model. The Journal of Positive Psychology, 6(1), 17-30. https://doi.org/10.1080/17439760.2010.536774

Suldo, S. M., \& Shaffer, E. J. (2008). Looking beyond psychopathology: The dual-factor model of mental health in youth. School Psychology Review, 37(1), 52-68.

Trompetter, H., Lamers, S., Westerhof, G. J., Fledderus, M., \& Bohlmeijer, E. T. (2017). Both positive mental health and psychopathology should be monitored in psychotherapy: Confirmation for the dual-factor model in acceptance and commitment therapy. Behaviour Research and Therapy, 91, 58-63. https://doi.org/10.1016/j.brat.2017.01.008

van Agteren, J., Iasiello, M., Lo, L., Bartholomaeus, J., Kopsaftis, Z., Carey, M. E., . . Kyrios, M. (Submitted). Psychological interventions to build positive mental health; A systematic review and meta-analysis.

van Erp Taalman Kip, R. M., \& Hutschemaekers, G. J. M. (2018). Health, well-being, and psychopathology in a clinical population: Structure and discriminant validity of Mental Health Continuum Short Form (MHC-SF). Journal of Clinical Psychology. https://doi.org/10.1002/jclp. 22621

Venning, A., Wilson, A., Kettler, L., \& Eliott, J. (2013). Mental health among youth in South Australia: A survey of flourishing, languishing, struggling, and floundering. Australian Psychologist, 48(4), 299-310. https://doi.org/10.1111/j.1742-9544.2012.00068.x

Windle, G., Bennett, K. M., \& Noyes, J. (2011). A methodological review of resilience measurement scales. Health and Quality of Life Outcomes, 9(1), 8. doi: 10.1186/1477-7525-9-8.

Wood, A. M., \& Joseph, S. (2010). The absence of positive psychological (eudemonic) well-being as a risk factor for depression: A ten year cohort study. Journal of Affective Disorders, 122(3), 213-217. https://doi.org/10.1016/j.jad.2009.06.032

Wu, H.-p., Garza, E., \& Guzman, N. (2015). International student's challenge and adjustment to college. Education Research International, 2015. http://dx.doi.org/10.1155/2015/202753

Xiong, J., Qin, Y., Gao, M., \& Hai, M. (2017). Longitudinal study of a dual-factor model of mental health in Chinese youth. School Psychology International, 38(3), 287-303. https://doi.org/10.1177\%2F0143034317689970

Yu, L., Shek, D. T., \& Zhu, X. (2018). The influence of personal well-being on learning achievement in university students over time: Mediating or moderating effects of internal and external university engagement. Frontiers in Psychology, 8 , 2287. https://doi.org/10.3389/fpsyg.2017.02287

\section{Please cite this article as:}

van Agteren, J., Woodyatt, L., Iasiello, M., Rayner, J., Kyrios, M. (2019). Make it measurable: Assessing psychological distress, wellbeing and resilience at scale in higher education. Student Success, 10(3), 1-13. https://doi.org/10.5204/ssj.v10i3.1411

This article has been peer reviewed and accepted for publication in Student Success. Please see the Editorial Policies under the 'About' section of the Journal website for further information.

Student Success: A journal exploring the experiences of students in tertiary education

(c) (1) This work is licensed under a Creative Commons Attribution 4.0 International Licence. As an open access journal, articles are free to use with proper attribution. ISSN: 2205-0795 